\title{
Effects of trastuzumab on the proliferation and apoptosis of ovarian cancer cells
}

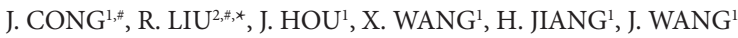 \\ ${ }^{1}$ Department of Gynecology and Obstetrics, Yantai Yuhuangding Hospital Affliated to Qingdao University, Yantai, Shandong Province, China; \\ ${ }^{2}$ Center for Laboratory Diagnosis, Yantai Yuhuangding Hospital Affiliated to Qingdao University, Yantai, Shandong Province, China \\ ${ }^{*}$ Correspondence: rimingliu724@163.com \\ ${ }^{\#}$ Contributed equally to this work.
}

Received July 24, 2018/ Accepted September 20, 2018

\begin{abstract}
This study investigates the effects of trastuzumab on the proliferation and apoptosis of ovarian cancer cells. Epithelial ovarian cancer tissues were collected from 60 patients, benign ovarian tissues from 45 patients and normal ovarian tissues from 30 patients. Human epidermal growth factor receptor 2 (HER2) protein expression was measured by immunohistochemistry and mRNA expression by quantitative real-time polymerase chain reaction (RT-PCR). Proliferation and apoptosis of SKOV3 cells were then measured by MTS assay and flow cytometry and cleaved caspase-3 expression was detected by Western blot. Our results established that HER2 protein is expressed in tumor tissues, benign tissues and normal tissues and its positive expression rate in tumor tissues is significantly higher than in benign tissues and normal tissues $(p<0.05)$. In addition, the relative HER2 mRNA expression in epithelial ovarian tumor tissues was 55 times higher than that in normal ovarian tissues $(\mathrm{p}<0.01)$. Our research confirmed that trastuzumab significantly inhibited SKOV3 cell proliferation and increased cell apoptosis and cleaved caspase-3 expression in the experimental group compared to controls $(p<0.05)$. In conclusion, HER2 protein is over-expressed in epithelial ovarian cancer tissues, and trastuzumab exerts anti-tumor effect by inhibiting cell proliferation and inducing apoptosis, suggesting it might be a novel approach for the treatment of ovarian cancer.
\end{abstract}

Key words: trastuzumab, ovarian cancer, cell proliferation, apoptosis

Ovarian cancer accounts for approximately $5 \%$ of female malignant tumors [1]. In China, the incidence ranks third in all female malignant tumors and it has a gradually increasing trend in recent years [2]. However, lack of specific detection methods for ovarian cancer means that patients are already in advanced stages at diagnosis. Radio- and chemotherapy are the main treatments for ovarian cancer, but patient 5-year survival rate remains low at 35\% [3,4]. Finally, the current rapid development of molecular biology and genetics now enables biological targeted therapy.

Human epidermal growth factor receptor 2 (HER2) is a proto-oncogene and it is abnormally expressed in a variety of malignant tumors, including gastric [5], esophageal [6] and pancreatic cancers [7]. The abnormal expression of HER2 gene is related to proliferation, metastasis and other biological behaviors of tumor cells in vivo [8]. Trastuzumab is a humanized monoclonal antibody against the extracellular domain of HER2 protein and it can effectively reduce the expression of HER2 and inhibit signal transduction [9]. While trastu- zumab is also widely used to treat metastatic breast cancer with HER2 over-expression [10], its precise role in ovarian cancer remains poorly understood. Herein, we investigated trastuzumab effect on ovarian cancer cell proliferation and apoptosis hoping to provide a theoretical basis for its efficacy in clinical treatment.

\section{Patients and methods}

Patients. A total of 60 patients with epithelial ovarian cancer and 45 patients with benign epithelial ovarian tumor were selected. These were diagnosed and underwent surgical excision at the Gynecology and Pathology Department of our hospital from May 2014 to May 2016. We also employed 30 normal ovarian tissues as controls. Histopathological diagnoses were performed according to the World Health Organization criteria [11]; with the study approved by the hospital ethics committee and informed consent obtained from all participants. 
Reagents. Mouse anti-human HER2 monoclonal antibody (BD), primary caspase-3 rabbit monoclonal antibody (Abcam, USA), streptavidin-peroxidase (S-P) immunohistochemistry kits (Beijing Baiaolaibo Technology, China), 3,3'-diaminobenzidine (DAB) color development reagents (Shanghai Xinyu Biotechnology Pharmaceutical, China), reverse transcription kits (Shanghai Yanqi Biotechnology, China), Roswell Park Memorial Institute (RPMI)1640 culture medium and trypsin (Gibco, USA), fetal bovine serum (Hangzhou Sijiqing Biological Engineering Material, China), 3-(4,5-dimethylthiazol-2-yl)-5-(3carboxymethoxyphenyl)-2-(4-sulfophenyl)-2H-tetrazolium (MTS) reagents (Shanghai Chengong Biological Technology, China), dimethyl sulfoxide (DMSO) (Shanghai Qiyi Biotechnology, China], Annexin V/propidium iodide (PI) staining kits (Shanghai Haoran Biological Technology, China), and trastuzumab (Roche, USA).

Immunohistochemistry. Paraffin sections were de-waxed, hydrated and then washed with phosphate buffer. In order to reduce the non-specific background staining caused by endogenous peroxidase, these sections were continuously blocked with the blocking solution for $20 \mathrm{~min}$ and sealed with $10 \%$ serum for 10 min. Primary antibody solution (mouse anti-human HER2 monoclonal antibody, diluted at 1:50) was added and incubated overnight at $4^{\circ} \mathrm{C}$. Sections were washed with phosphate buffer, followed by the addition of secondary antibody solution diluted to 1:50 and incubation for $30 \mathrm{~min}$ at room temperature; and they were then washed with phosphate buffer and incubated with streptomyces antibiotic protein-peroxidase solution for half an hour at room temperature. Phosphate buffer solution was used for washing, followed by $\mathrm{DAB}$ color development and rinsing with distilled water. After counterstaining and sealing, the sections were observed under a microscope.

Immunohistochemistry sections were assessed under optical microscope and scored according to coloration degree: 0 point for no coloration, 1 point for light yellow and 2 points for medium brown. The sections were then scored for proportion of positive cells: 1 point for $<10 \%, 2$ points for $10-50 \%$, 3 points for $50-75 \%$, and 4 points for $>75 \%$. The product of the coloration degree score and the positive cell proportion score was taken as the final staining score. (-): 0 points, (+): 1-4 points, $(++): 5-8$ points, and $(+++): 9-12$ points

Quantitative real-time polymerase chain reaction (RT-PCR). Total ribonucleic acid (RNA) was extracted from ovarian cancer tissues and normal ovarian tissues, and complementary deoxyribonucleic acid (cDNA) was synthesized using a reverse transcription kit in a $20 \mu \mathrm{l}$ reverse transcription system consisting of $4 \mu \mathrm{l} 5 \times$ PrimeScript Buffer, $1 \mu \mathrm{l}$ PrimeScipt RT Enzyme Mix, $1 \mu$ l PrimeScript RT Enzyme Mix, $10 \mu \mathrm{l}$ of the above reaction solution, and $4 \mu \mathrm{l}$ RNase-free $\mathrm{dH}_{2} \mathrm{O}$, at $37^{\circ} \mathrm{C}$ for $15 \mathrm{~min}$, and at $85^{\circ} \mathrm{C}$ for $5 \mathrm{~s}$. PCR reaction was then performed in a volume of $25 \mu \mathrm{l}$ system, including $12.5 \mu$ SYBR Premix Ex Taq ${ }^{\text {Tw }}$ II, $1 \mu$ l forward primer, $1 \mu \mathrm{l}$ reverse primer, $2 \mu \mathrm{l} \mathrm{cDNA}$, and $8.5 \mu \mathrm{d}_{2} \mathrm{O}$. The reaction conditions were as follows: pre-denaturation at $94^{\circ} \mathrm{C}$ for $3 \mathrm{~min}$, denaturation at $94^{\circ} \mathrm{C}$ for $20 \mathrm{~s}$, annealing at $58^{\circ} \mathrm{C}$ for $20 \mathrm{~s}$, extension for $30 \mathrm{~s}$, and a total of 40 cycles. The relative expression of HER2 mRNA was calculated using $2^{-\Delta \Delta} \mathrm{CT}$ and $\beta$-actin as internal reference control. Primers were synthesized by Huamei (International) Bio-Engineering Co., Ltd. Primer sequences: HER2: forward: 5'-CTGCCTGTCCCTACAACTACCTTTC-3', reverse: 5'-CACCGCTGTGTTCCAATCCTCT-3', and $\beta$-actin: reverse: 5'-AGCGAGCATCCCCCAAAGTT-3', reverse: 5'-GGGCACGAAGGCTCATCATT-3'.

Detection of SKOV 3 proliferation by MTS assay. Ovarian cancer cell line SKOV3 was purchased from Shanghai Suer Biological Technology Co., Ltd. Cells in the logarithmic growth phase were digested and centrifuged, the supernatant was discarded and cell suspension was prepared at a concentration of $1 \times 10^{5} / \mathrm{ml}$. A $100 \mu$ l cell suspension was added to the wells of a 96-well plate, and five replicate wells were set in each group. Cells were placed in an incubator for further culture for 24 hours followed by division into the control group of SKOV3 cells and RPMI-1640 culture medium, the blank group with the same amount of RPMI-1640 culture medium and the trastuzumab groups with $5 \mu \mathrm{g} / \mathrm{l}, 10 \mu \mathrm{g} / \mathrm{l}$, $20 \mu \mathrm{g} / \mathrm{l}, 40 \mu \mathrm{g} / \mathrm{l}$ and $80 \mu \mathrm{g} / \mathrm{l}$ trastuzumab. $10 \mu \mathrm{l}$ MTS reagents were added to each well after 48 hours and the Sunrise microplate reader detected optical density of each well at $490 \mathrm{~nm}$ after 3 hours further culture.

Detection of cell apoptosis by flow cytometry. Cultured cells were re-suspended in $1 \times$ Binding Buffer followed by addition of $5 \mu \mathrm{l}$ Annexin $\mathrm{V}$-fluorescein isothiocyanate (FITC), mixed evenly and incubated in the dark for 15 minutes. $5 \mu \mathrm{l}$ PI was then added for staining and cell apoptosis was measured by flow cytometry.

Measurement of the expression of cleaved caspase- 3 by western blot. Total protein was extracted by RIPA lysis buffer and concentration was determined by bicinchoninic acid (BCA) protein assay. Proteins were separated on SDS-PAGE followed by transfer to PVDF membrane. The membrane was blocked with $5 \%$ nonfat dry milk for 90 minutes at $37^{\circ} \mathrm{C}$ followed by incubation with primary antibody (diluted at 1:1,000) overnight at $4^{\circ} \mathrm{C}$. After washing with tris-buffered saline with Tween 20 (TBST) solution, the membrane was incubated with 1:1,000 HRP-conjugated secondary antibody at $37^{\circ} \mathrm{C}$ for 1 hour. Enhanced chemiluminescence (ECL) solution was added for coloration, followed by exposure, development and fixation. Finally, the ChemiDocTMMP imaging system was used for scanning and data was analyzed by ImageJ software. The protein expression of cleaved caspase- 3 is presented as the ratio relative to pro-caspase- 3 .

Statistical analysis. Statistical Product and Service Solutions (SPSS) 20.0 software was used to analyze the data. Measurement data were expressed as mean \pm standard deviation (SD) from three independent in vitro experiments. One-way analysis of variance compared multiple groups and the Student t-test compared the mean value of two samples, with $\mathrm{p}<0.05$ indicating statistical significance. 


\section{Results}

Increased HER2 protein expression in tumor tissues. Figure 1 and Table 1 show that HER2 protein was expressed in tumor tissues, benign tissues and normal tissues with positive rates of $43.33 \%, 15.56 \%$ and $6.67 \%$, respectively. The positive rate of HER2 protein in tumor tissues was significantly higher than those in benign and normal tissues $(p<0.05)$. However, there was no significant difference between benign tissues and normal tissues ( $p>0.05)$.

Elevated expression of HER2 mRNA in tumor tissues. RT-PCR analysis showed that the relative expression of HER2 mRNA in epithelial ovarian tumor tissue was approximately 55 times higher than that in normal ovarian tissue with a statistically significant difference $(\mathrm{p}<0.01$, Table 2$)$.

Trastuzumab inhibits proliferation of SKOV 3 cells. MTS assay demonstrated that trastuzumab significantly inhibited the proliferation of SKOV3 cells in a dose-dependent manner (Figure 2). There was also statistically significant difference between experimental and control groups $(\mathrm{p}<0.05)$.

Trastuzumab increases SKOV3 cell apoptosis. Figure 3 shows that after treatments with trastuzumab at different concentrations for 48 hours, the apoptotic rates in the experimental group were $(12.0 \pm 1.3),(20.2 \pm 1.8)$ and $(25.1 \pm 2.1)$, respectively, and significantly higher than in controls $(6.4 \pm 1.6$,
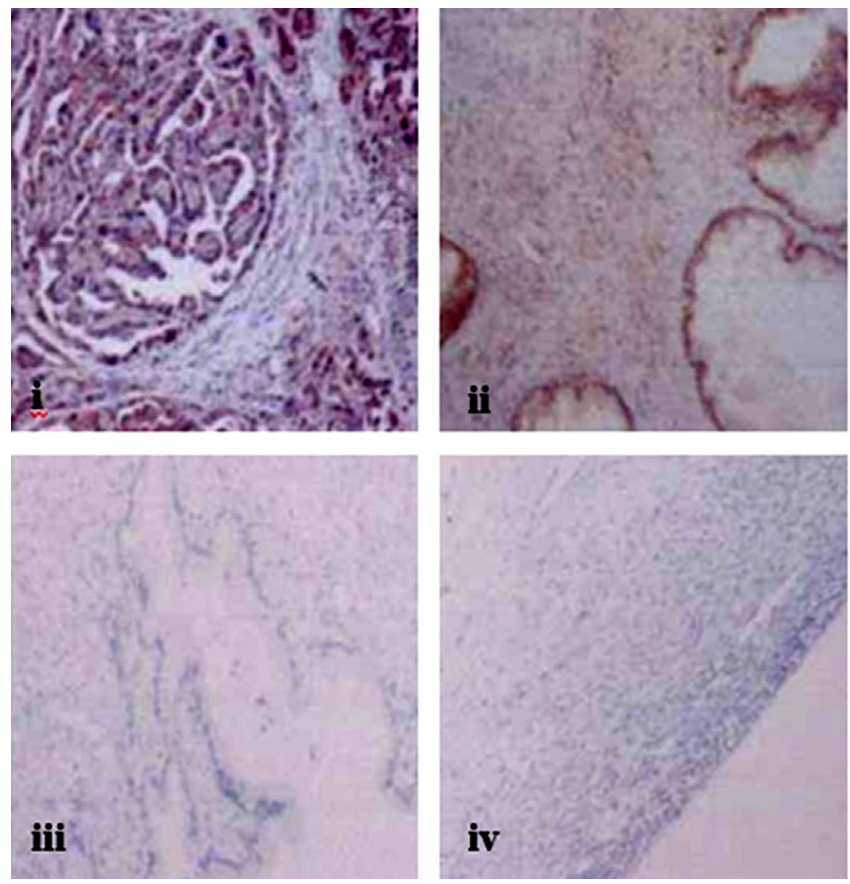

Figure 1. HER2 expression in ovarian cancer. Ovarian cancer tissues were isolated from patients with ovarian cancer and HER2 expression was measured by immunohistochemical staining. i: HER2 positive expression in ovarian serous cystadenoma, ii: HER2 positive expression in ovarian mucinous cystadenoma, iii: HER2 negative expression in ovarian mucinous cystadenoma, and iv: HER2 positive expression in the normal ovary.
Table 1. Expression of HER2 protein in epithelial ovarian tumor tissues.

\begin{tabular}{lcccc}
\hline & n & n (positive) & Positive rate $(\%)$ & p-value \\
\hline Tumor tissue & 60 & 26 & 43.33 & $0.006^{\mathrm{a}}$ \\
Benign tissue & 45 & 7 & 15.56 & $0.024^{\mathrm{b}}$ \\
Normal tissue & 30 & 2 & 6.67 & $0.439^{\mathrm{c}}$ \\
\hline
\end{tabular}

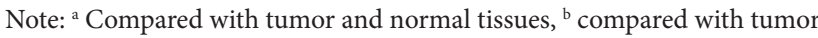
and benign tissues, and ${ }^{\mathrm{c}}$ compared with benign and normal tissues.

Table 2. Expression of HER2 mRNA in epithelial ovarian cancer tissues.

\begin{tabular}{|c|c|c|c|c|}
\hline & \multicolumn{2}{|c|}{ HER2 } & \multirow{2}{*}{ t-value } & \multirow{2}{*}{ p-value } \\
\hline & $\Delta \mathrm{CT}$ & $2^{-\Delta \Delta C T}$ & & \\
\hline Tumor tissue & 13.19 & \multirow{2}{*}{55.18} & \multirow{2}{*}{9.27} & \multirow{2}{*}{$<0.01$} \\
\hline Normal tissue & 19.04 & & & \\
\hline
\end{tabular}

$\mathrm{p}<0.05)$. There was also significant difference in cell apoptotic rate between experimental control groups $(p<0.05$, Figure 3$)$.

Trastuzumab increased expression of cleaved caspase- 3 . Treatment with trastuzumab at different concentrations for 48 hours led to the following expression of cleaved caspase- 3 expressions in the experimental group $0.43 \pm 0.02,0.65 \pm 0.03$ and $0.68 \pm 0.03$, respectively, and these were significantly higher than in controls $(0.35 \pm 0.02)(\mathrm{p}<0.05)$. There was also significant difference in the experimental and control groups $(\mathrm{p}<0.05$, Figure 4$)$.

\section{Discussion}

Ovarian cancer is relatively more common than other female reproductive system tumors. Since there is no current precise and effective treatment, investigating the occurrence and development mechanisms of ovarian cancer, identifying

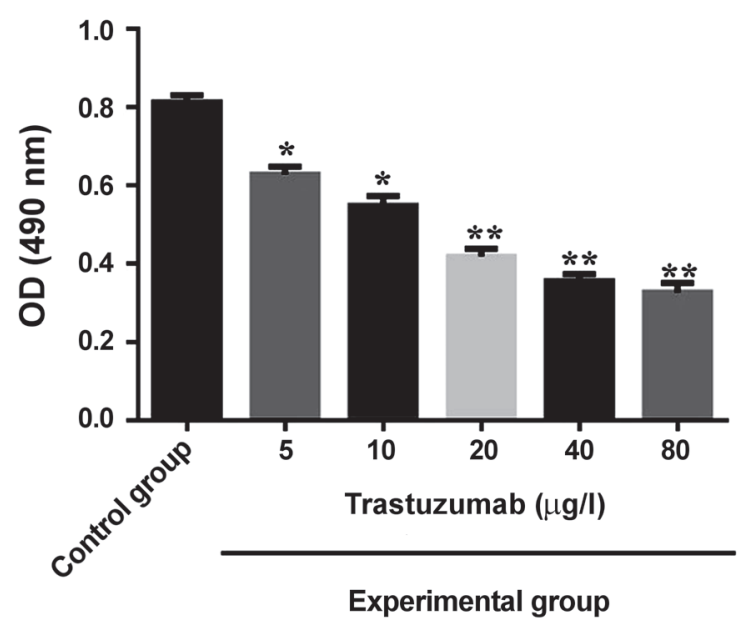

Figure 2. Effect of Trastuzumab on the proliferation of SKOV3 cells. Ovarian cancer cell line SKOV3 was cultured in the presence and absence of trastuzumab $(5 \mu \mathrm{g} / \mathrm{l}, 10 \mu \mathrm{g} / \mathrm{l}, 20 \mu \mathrm{g} / \mathrm{l}, 40 \mu \mathrm{g} / \mathrm{l}$, and $80 \mu \mathrm{g} / \mathrm{l})$ and cell proliferation was measured by MTT assay. Compared with control group; ${ }^{*} \mathbf{p}<0.05 ;{ }^{* *} \mathbf{p}<0.01$. 

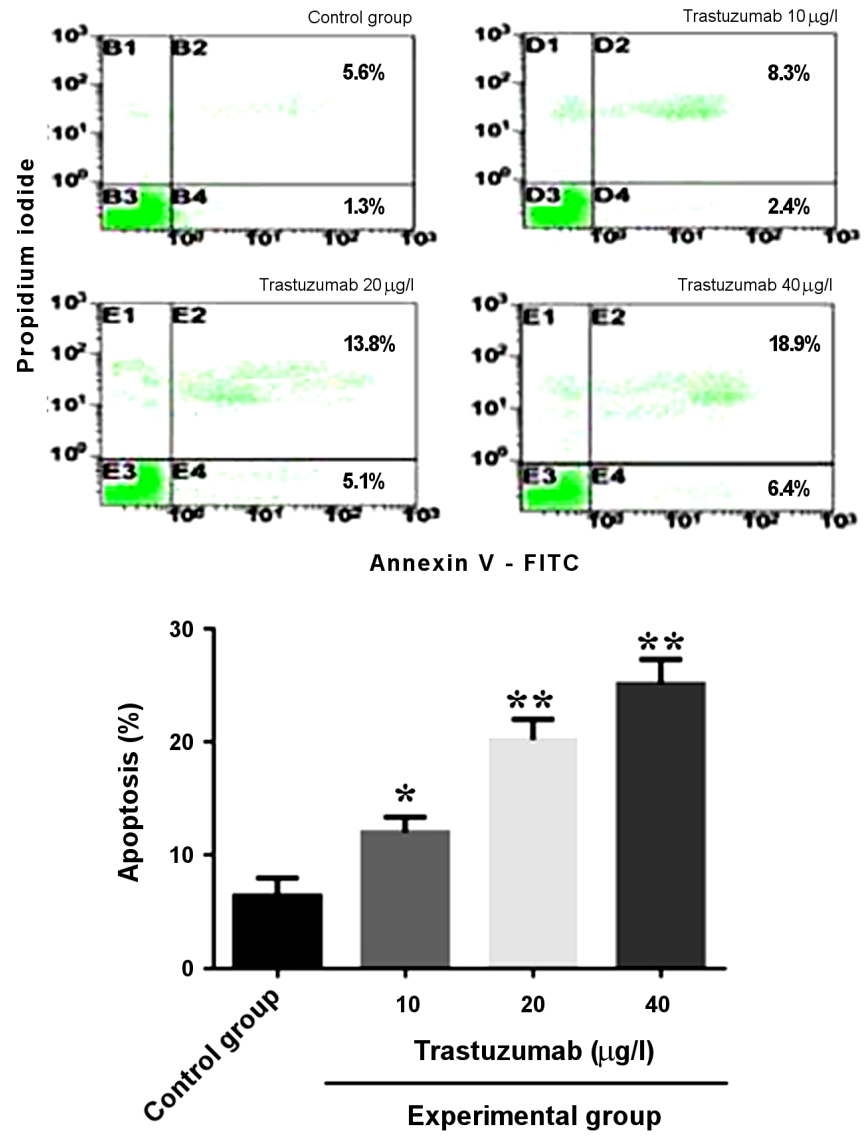

Figure 3. Analysis of SKOV3 cell apoptosis after treated with trastuzumab. After treatment with differing Trastuzumab concentrations, cell apoptosis was measured by flow cytometry using FITC-conjugated Annexin-V. Compared with control group; ${ }^{\star} \mathrm{p}<0.05 ;{ }^{\star *} \mathrm{p}<0.01$.

associated molecular markers and finding a bio-targeted therapy have vital clinical significance in improving patient prognosis.

HER2 is a proto-oncogene which encodes a transmembrane glycoprotein, and its over-expression is involved in the regulation of abnormal proliferation, differentiation and anti-apoptotic processes [12-13]. The HER2 gene is over-expressed in many malignant tumors [14] and trastuzumab, which targets HER2, has been successfully used in the treatment of metastatic breast cancer with HER2-overexpression [15].There has been recent study on HER2 expression in ovarian cancer and its relationship with prognosis [16], and some researchers have found that HER2 gene expression has a key role in the occurrence and development of epithelial ovarian cancer; with the 5-year survival rate of patients with HER2 over-expression significantly decreased [17], suggesting it might be used as a poor prognostic factor. This supports our finding that HER2 expression in ovarian cancer tissues is significantly higher than in normal ovarian tissues and suggests it is involved in the cancer's occurrence and development.
Trastuzumab is an exogenous monoclonal antibody targeting HER2, but its precise anti-tumor mechanism is not fully understood. Studies have confirmed two important factors leading to human tumor occurrence and development: (1) cell proliferation and differentiation abnormalities [18] and (2) impaired cell apoptosis [19]. Influencing and correcting the tumor cell cycle and its regulatory role in targeted tumor treatment is therefore clinically important.

Herein, the inhibitory effects of different concentrations of trastuzumab on SKOV3 cell proliferation were determined by MTS assay and revealed that increasing trastuzumab concentrations significantly improved the inhibitory effect on SKOV3 cell proliferation in a dose-dependent manner Annexin V/PI staining flow cytometry analysis of the cell apoptosis showed that the apoptosis rate of SKOV3 cells was significantly increased with the increase of trastuzumab concentration. Since the characteristics of apoptosis could not be detected by a single effective method, the early apoptotic protein cleaved caspase- 3 was detected by Western blot at the same time andrevealed that the content of cleaved caspase- 3 was increased with the increase of trastuzumab concentration, suggesting that trastuzumab can effectively induce apoptosis of ovarian cancer cell lines through upregulation of cleaved caspase-3, which was consistent with a previous study demonstrating that trastuzumab can exhibit
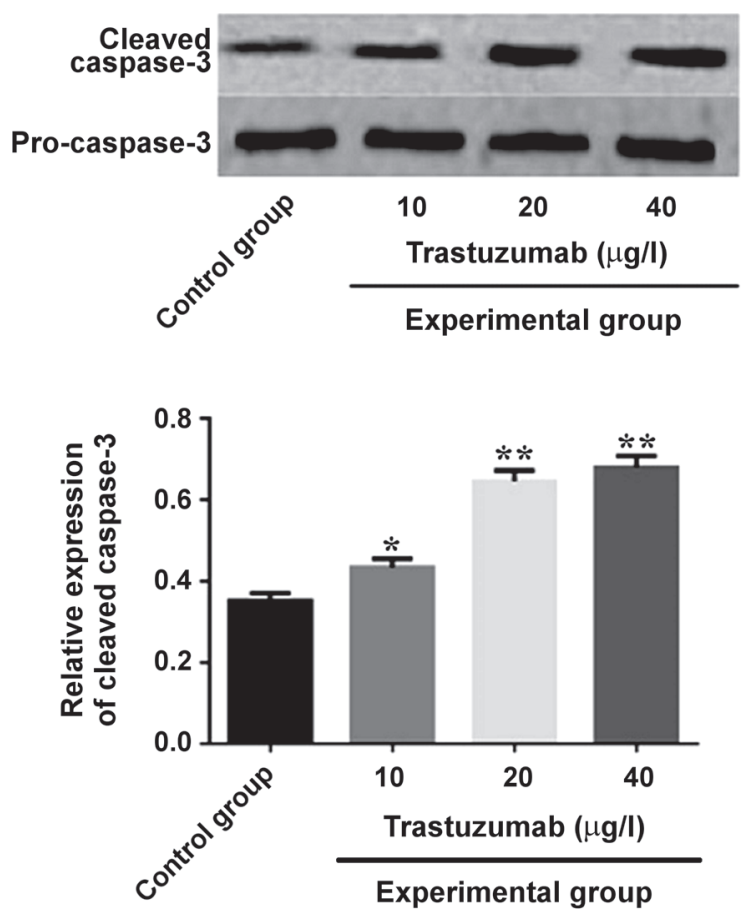

Figure 4. Effects of Trastuzumab on the expression of cleaved caspase-3. SKOV3 cells were treated with different doses of Trastuzumab and cleaved caspase- 3 expression was measured by Western blot. The cleaved caspase- 3 expression was quantified as the ratio relative to pro-caspase- 3 . Compared with control group, ${ }^{\star} \mathrm{p}<0.05 ;{ }^{*} \mathrm{p}<0.01$. 
anti-tumor activity and effectively promote cell apoptosis [20]. However, the exact mechanism by how trastuzumab induces apoptosis of SKOV3 cells remains unclear and requires further investigations.

In conclusion, trastuzumab significantly inhibits ovarian cancer SKOV3 cell proliferation and promotes their apoptosis. This provides a theoretical support for the application of HER2 targeted therapy in epithelial ovarian cancer treatment.

Acknowledgments: This study was generously supported by Shandong Provincial Natural Science Foundation, China (ZR2016HL37).

\section{References}

[1] GSTOTTNER M, ANGERER A, ROSIEK R, BACH CM. Quantitative volumetry of cement leakage in viscosity-controlled vertebroplasty. J Spinal Disord Tech 2012; 25: E150154. https://doi.org/10.1097/BSD.0b013e31823f62b1

[2] MATSUZAKI S, YOSHINO K, UEDA Y, MATSUZAKI S, KAKUDA $M$ et al. Potential targets for ovarian clear cell carcinoma: a review of updates and future perspectives. Cancer Cell Int 2015; 15: 117. https://doi.org/10.1186/s12935-0150267-0

[3] KESAVAN A, ILAIYARAJA P, SOFI BEAULA W, VEENA KUMARI V, SUGIN LAL J et al. Tumor targeting using polyamidoamine dendrimer-cisplatin nanoparticles functionalized with diglycolamic acid and herceptin. Eur J Pharm Biopharm 2015; 96: 255-263. https://doi.org/10.1016/j. ejpb.2015.08.001

[4] YU L, WANG Y, YAO Y, LI W, LAI Q et al. Eradication of growth of HER2-positive ovarian cancer with trastuzumabDM1, an antibody-cytotoxic drug conjugate in mouse xenograft model. Int J Gynecol Cancer 2014; 24: 1158-1164. https://doi.org/10.1097/IGC.0000000000000179

[5] JIA Y, ZHANG Y, QIAO C, LIU G, ZHAO Q et al. IGF1R and ErbB3/HER3 contribute to enhanced proliferation and carcinogenesis in trastuzumab-resistant ovarian cancer model. Biochem Biophys Res Commun 2013; 436: 740-745. https://doi.org/10.1016/j.bbrc.2013.06.030

[6] SU F, GENG J, LI X, QIAO C, LUO L et al. SP1 promotes tumor angiogenesis and invasion by activating VEGF expression in an acquired trastuzumab-resistant ovarian cancer model. Oncol Rep 2017; 38: 2677-2684. https://doi. org/10.3892/or.2017.5998

[7] KHALIL HS, LANGDON SP, GOLTSOV A, SOININEN T, HARRISON DJ et al. A novel mechanism of action of HER2 targeted immunotherapy is explained by inhibition of NRF2 function in ovarian cancer cells. Oncotarget 2016; 7: 7587475901. https://doi.org/10.18632/oncotarget.12425

[8] LOPEZ-ALBAITERO A, XU H, GUO H, WANG L, WU $\mathrm{Z}$ et al. Overcoming resistance to HER2-targeted therapy with a novel HER2/CD3 bispecific antibody. Oncoimmunology 2017; 6: e1267891. https://doi.org/10.1080/216240 2X.2016.1267891
[9] HODEIB M, SERNA-GALLEGOS T, TEWARI KS. A review of HER2-targeted therapy in breast and ovarian cancer: lessons from antiquity - CLEOPATRA and PENELOPE. Future Oncol 2015; 11: 3113-3131. https://doi.org/10.2217/ fon. 15.266

[10] MEREDITH RF, TORGUE J, AZURE MT, SHEN S, SADDEKNI $S$ et al. Pharmacokinetics and imaging of $212 \mathrm{~Pb}$ TCMC-trastuzumab after intraperitoneal administration in ovarian cancer patients. Cancer Biother Radiopharm 2014; 29: 12-17. https://doi.org/10.1089/cbr.2013.1531

[11] Karseladze AI. [WHO histological classification of ovarian tumors. Geneva, 1999 (R.E.Scully, L.H.Sobin]. Arkh Patol 2005; Suppl: 1-64.

[12] MOHAMMED RAA, MAKBOUL R, ELSERS DAH, ELSABA TMAM, THALAB AMAB et al. Pattern of HER-2 Gene Amplification and Protein Expression in Benign, Borderline, and Malignant Ovarian Serous and Mucinous Neoplasms. Int J Gynecol Pathol 2017; 36: 50-57. https://doi. org/10.1097/PGP.0000000000000302

[13] CHAO WR, LEE MY, LIN WL, CHEN CK, LIN JC et al. HER2 amplification and overexpression are significantly correlated in mucinous epithelial ovarian cancer. Hum Pathol 2014; 45: 810-816. https://doi.org/10.1016/j.humpath.2013.11.016

[14] MORIMURA O, MINAMI T, KIJIMA T, KOYAMA S, OTSUKA T et al. Trastuzumab emtansine suppresses the growth of HER2-positive small-cell lung cancer in preclinical models. Biochem Biophys Res Commun 2017; 488: 596-602. https://doi.org/10.1016/j.bbrc.2017.05.090

[15] MENDERES G, BONAZZOLI E, BELLONE S, ALTWERGER G, BLACK JD et al. Superior in vitro and in vivo activity of trastuzumab-emtansine (T-DM1) in comparison to trastuzumab, pertuzumab and their combination in epithelial ovarian carcinoma with high HER2/neu expression. Gynecol Oncol 2017; 147: 145-152. https://doi.org/10.1016/j. ygyno.2017.07.009

[16] SABBAGHI M, GIL-GOMEZ G, GUARDIA C, SERVITJA $\mathrm{S}$, ARPI $\mathrm{O}$ et al. Defective Cyclin B1 Induction in Trastuzumab-emtansine (T-DM1) Acquired Resistance in HER2positive Breast Cancer. Clin Cancer Res 2017; 23: 7006-7019. https://doi.org/10.1158/1078-0432.CCR-17-0696

[17] ENGLISH DP, ROQUE DM, SANTIN AD. HER2 expression beyond breast cancer: therapeutic implications for gynecologic malignancies. Mol Diagn Ther 2013; 17: 85-99. https://doi.org/10.1007/s40291-013-0024-9

[18] MENYHART O, SANTARPIA L, GYORFFY B. A Comprehensive Outline of Trastuzumab Resistance Biomarkers in HER2 Overexpressing Breast Cancer. Curr Cancer Drug Targets 2015; 15: 665-683. https://doi.org/10.2174/1568009 61508151001101742

[19] BULL-HANSEN B, BERSTAD MB, BERG K, CAO Y, SKARPEN E et al. Photochemical activation of MH3B1/rGel: a HER2-targeted treatment approach for ovarian cancer. Oncotarget 2015; 6: 12436-12451. https://doi. org/10.18632/oncotarget.3814

[20] HUANG R, SUN Y, GAO Q, WANG Q, SUN B. Trastuzumab-mediated selective delivery for platinum drug to HER2positive breast cancer cells. Anticancer Drugs 2015; 26: $957-$ 963. https://doi.org/10.1097/CAD.0000000000000272 